\title{
Utilizing Edmodo and Google Classroom for Facilitating Blended Learning
}

\author{
Sugeng Susilo Adi \\ English Language Education Program \\ Univeritas Brawijaya \\ Malang, Indonesia \\ sugengadi@ub.ac.id
}

\begin{abstract}
The advancement of information technology and communication (ITC) affects the teaching and learning strategy where blended learning has been very popular applied in some universities. This article describes the students' perception and learning experiences in utilizing Edmodo and Google Classroom for blended learning model at the English Education Study Program, Faculty of Cultural Studies, Universitas Brawijaya. Three parallel classes in Cross Cultural Understanding ( $\mathrm{CCU}$ ) course and three of Introduction to Education were employed in this observation. Qualitative observation, and online interviews were conducted to gain students pedagogical interaction, learning experiences, and expectation about blended learning strategy. The study reveals that students have new perspectives about the role of culture in communication especially the use of language as a medium of communication. The blended learning strategy makes the students find it interesting. The strategy motivates their learning activities because they can explore the learning activities using and the media used is similar to social media those they have been very familiar with their daily life. They say that expressing opinions and answering questions in the media are more independent than in the conventional classrooms because they do not lose their face and not getting immediate feedback form friends and the lecturer.
\end{abstract}

Keywords-Google Classroom; Edmodo; cross cultural understanding; perceptions; experience

\section{INTRODUCTION}

Blended learning can be defined as the combination of multiple approaches to pedagogy or teaching, e.g. self-paced, collaborative, tutor-supported learning or traditional classroom teaching. Blended learning often refers specifically to the provision or use of resources which combine e-learning with other educational resources. Some authors talk about "hybrid learning", "mixed learning" or "multimethod-learning". However, all of these concepts broadly refer to the integration (the "blending") of e-learning tools and techniques with traditional methods. Computer-based learning is no longer regarded as an alternative to traditional forms of learning/teaching. It is integrated into a learning arrangement which combines those methods that have been selected for a specific learning purpose or environment. Blended learning is not really a new concept. Teachers have always been using 'combined resources'. Basically, blended learning is just a combination of teaching or facilitation methods, learning styles, resource formats, a range of technologies and a range of expertise [1].

According to Strauss, he argues that in blended learning, where students' face-to-face education is blended with Internet resources or online courses, it has been gaining considerable attention in education reform circles [2]. It has become entangled with the ambiguous notion of personalized learning and is being positioned as the new way to individualize learning in competency-based education systems. Michael Horn, co-founder of the Clayton Christensen Institute for Disruptive Innovation, and a key proponent of blended learning, claims that it is the "new model that is student-centric, highly personalized for each learner, and more productive, as it delivers dramatically better results at the same or lower cost" [2].

Adi adds that the reason which has always been cited for the benefit of blended learning is the teacher can select and sort curriculum contents and learning activities, whether online or face to face, based on the level of difficulty, interests, and learning styles of students [3]. Furthermore, the teacher can let students decide when to learn at their own discretion as well as what to do if they cannot attend the face-to-face sessions. In the context of learning, blended learning can be implemented with adjustments and modifications accordingly with the conditions of the school. With blended learning, it is expected that students and teachers develop a culture of technological competence within themselves, and also a culture of critical thinking and inquiry within students by comparing or elaborating materials provided by teachers with resources that are virtually available. Blended learning can be utilized as an information sharing medium with other parties that are concerned with the development of education and scientific study of their fields. Through blended learning, teachers can sort a compressed curriculum and present it face-to-face or online, in the process increasing the quality of learning which leads to an increase in learning retention. Based on the development of technology which can be utilized for learning, at this time there is no single ideal learning method for all types of learning or training, because any form of technology has its own advantages. As well, blended learning allows learning to become more professional to handle learning needs in a way that is most effective and efficient, and has high appeal [3]. 
The effectiveness of applying blended learning is the support from the institution. Seta, Wati \& Matondang [4] say that the management of the faculty in higher education needs to improve the infrastructure especially internet bandwith both inside and outside the classroom.

In addition, in their Edmodo Multimedia: Supporting Technology for Media Learning at Higher Education, Puji and Umamah state that the use of Edmodo enables to provide facilities and ease in developing the interaction between teachers and also learners [5]. Edmodo is one of the online-based media with the support of features that are very complete so it is suitable for various types of education. Utilization of Edmodo has a creative and educative function to learners through the exploration of technological skills in learning. Another research conducted by Lina reveals that the use of Edmodo in teaching process of writing skill is quite familiar for teachers, and student-teacher interaction could happen in a virtual classroom [6].

Another mode of instructional media which is currently famous is Google Classroom. Some scholars are interested in exploring about issues dealing with the application of blended learning mediated by the Google Classroom. According to Azhar and Iqbal in their Effectiveness of Google Classroom: Teachers' Perceptions explains that Google classroom as only a facilitation tool that can be used for document management and basic classroom management, without having a significant impact on teaching methodologies [7]. The responses of the teachers indicate that lack of user-friendly interface is the main reason for its inefficiency. In addition, Strauss found that majority of the students satisfy with the Google Classroom's tool that were introduced in the class. Results of data analyzed showed that all ratios are above averages. In particular, comparative performance is good in the areas of ease of access, perceived usefulness, communication and interaction, instruction delivery and students' satisfaction towards the Google Classroom's active learning activities [2].

The blended learning model has been applied in Universitas Brawijaya Malang since 2015. Students and lecturers have used the media for facilitating their teaching processes. Pradana, Rachmadi \& Bachtiar concludes that faculty members prefer the other system to the univeristy one becuase the second is less effective in facilitating learning [8].

For those above-mentioned reasons, this article tries to illuminate the students' perception and learning experiences in utilizing Edmodo and Google Classroom for blended learning model at the English Education Study Program, Faculty of Cultural Studies, Universitas Brawijaya.

\section{METHOD}

This research employs qualitative exploration using interviews, observation, and document reviewing to collect the data. This research is directed to gain details of description about the background, general and specific characteristics particulary about the implementation of blended learning. The obtained data were used to be a fundemental in discussing the research objectives escriptively. This research didn't give any treatment to the research subjects, instead of just using interviews, observation, and document reviews.

The research was conducted in the Program of English Language Education, Department of Language Education, Faculty of Cultural Studies, Universitas Brawijaya, Malang. Three parallel classes in Cross Cultural Understanding (CCU) course and three of Introduction to Education were employed in this observation. Qualitative observation, document review, and online interviews were conducted to gain students pedagogical interaction, learning experiences, and expectation about blended learning strategy.

\section{RESUlTS AND DISCUSSION}

\section{A. Using Edomodo for CCU Subjects}

In 2013, the researcher observed the blended learning for CCU class which is mediated by a social-media like, an educational online system called Edmodo. It is an educational website that takes the ideas of a social network and refines them and makes it appropriate for a classroom. Using Edmodo, students and teachers can reach out to one another and connect by sharing ideas, problems, and helpful tips. A teacher can assign and grade work on Edmodo; students can get help from the entire class on Edmodo. It is a safe environment. There is no bullying or inappropriate content, because the teacher can see everything that is posted on Edmodo. Also, parents can join the class to bring a level of transparency that is difficult to achieve without technology. All in all, Edmodo is a great companion to just about any class.

Edmodo helps the researcher particularly when he is not able to attend to the offline classes, he can post teaching materials, assignments, or learning resources using the online model. The use of Edmodo for the Cross-Cultural Understanding course was also to support the offline sessions. In Edmodo, students do not relatively find any difficulty because the appearance of Edmodo is familiar to them due to the fact that it resembles other forms of social media, in particular Facebook. The researcher tried to make use of Edmodo (located at http://www.edmodo.com), a learning medium in a social media format using an attractive appearance styled after popular culture, to manage five courses. The researcher uses the Edmodo medium as a complement to offline sessions, conventional courses with face-to-face interaction. Edmodo was chosen as the online session medium because the medium has some features which were believed to be appropriate for students and learning management. In addition, the appearance of Edmodo which resembles other social media such as Facebook became a consideration in selecting this medium to manage the aforementioned five classes. With this appearance, hopefully students felt comfortable and learning became fun for them, and at the same time they did not feel as if they are learning but virtually interacting like in social media.

This Figure 1 below shows the researcher's Edmodo mediated classroom, and Figure 2 shows some classroom groups under the researcher supervision. 


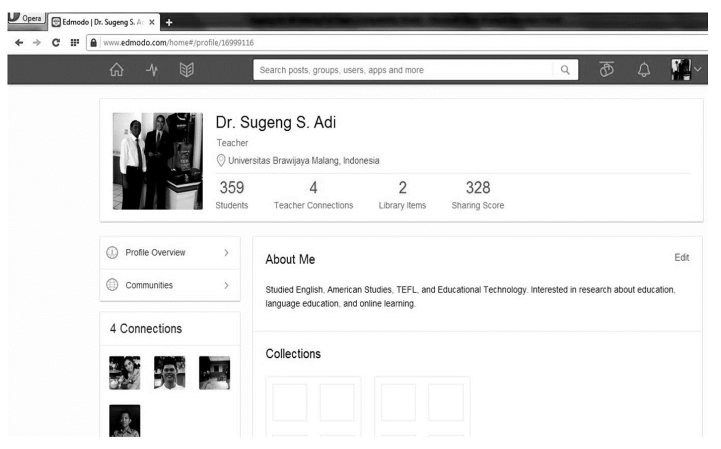

Fig. 1. The researcher's Edmodo Account

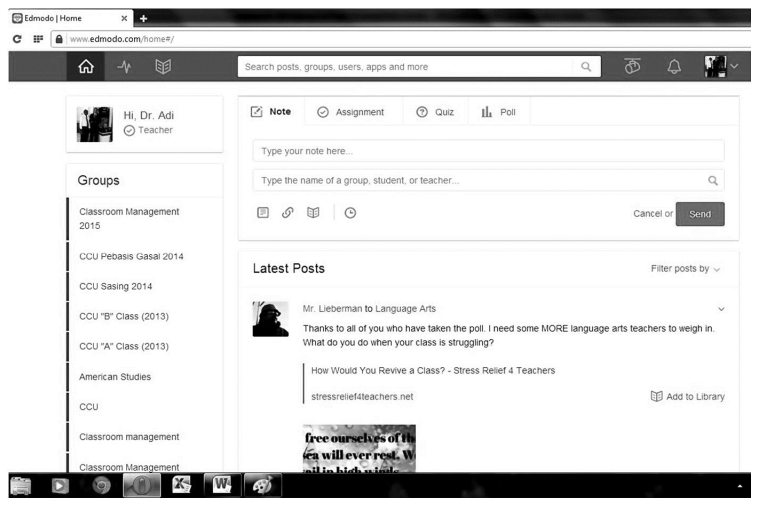

Fig. 2. Classroom Groups

Online session in blended learning cold make students learn independently. Hung says that students who have the ability to learn independently are considerably more likely to perform successfully in online-education contexts than are students who lack this ability [9].

Edmodo as the media to support independent learning, has a few learning tools which support the process of planning, management, and evaluation of learning. In learning planning, Edmodo allows the lecturer to post the semester course plan as well as to provide the learning resources in different formats, whether textual, audiovisual, or multimedia. In learning management, the lecturer can post assignments, quizzes, and discussion topics, as well as to facilitate a discussion forum among students. In learning evaluation, the lecturer can give feedback regarding the learning progress using the grading feature provided. The lecturer can give feedback on structured assignments, midterm and final examinations, as well as quizzes using an array of interesting icons. Students can use this medium to post their learning "status" like in Facebook, turn in assignments, answer questions, be actively involved in online discussion, and comment on other students' "status" [3].

Table 1 below shows the students' pedagogical interaction in the Cross-Cultural Understanding subject applying blended learning mode of instruction. Among 14 meetings, 7 topics of discussion were mediated by Edmodo online system. Among 51 students, it is only in the final test that all students are answering the lecturers' questions. In the final test, two out of 51 students are not answering the question items. Interestingly, the students collected the answers in a printed form after reading the questions in the online learning session.

TABLE I. PEDAGOGICAL INTERACTION IN ONLINE SESSION USING EMODO

\begin{tabular}{|c|c|c|c|}
\hline \multicolumn{4}{|c|}{ Edmodo Reflection } \\
\hline \multicolumn{4}{|c|}{ Subject: Cross-Cultural Understanding (51 students) } \\
\hline & Assignment topic & Turned-in & Feedback \\
\hline 1. & Introduction to $\mathrm{CCU}$ & 38 & \\
\hline 2. & Verbal patterns & 45 & \\
\hline 3. & Mid-semester test & 51 & 51 \\
\hline 4. & Friendship & 43 & \\
\hline 5. & Family Values & 50 & \\
\hline 6. & Education Values & 47 & \\
\hline 7. & Final test & 49 & \\
\hline
\end{tabular}

\section{B. Utilizing Google Classroom for Blended Learning}

In 2019, the researcher tries to use Google Classroom, another social media like for facilitating teaching and learning process. Three parallel classes of Cross Cultural Understanding and three parallels of Introduction to Education were used to facilitate the lectures. Similar to the previous model of Edmodo, Google Classroom provides both students and teachers to interact in the virtual classroom not only synchronously but also asynchronously. Various modes of facilities provided to the users to conduct pedagogical interaction. For the teachers, they can post many types of activities such as posting teaching materials in any types of format like pdf text, power point presentation, hyperlink to website resources, or video. Lecturing could be more flexible because this media could be utilized for many activities like quiz, questions, discussion forum, semester or mid semester tests, and assignments.

In their Google Classroom as a Tools for Active Learning, Shaharanee, Jamil, \& Rodzi say that Google classroom is useful in helping in the teaching and learning process, as its ease of use they will intend to use it when needs arise [10]. The teacher uphill tasks are to make students aware of its use in future workplace, as well as to ensure students confidence that it is easy to use. Google classroom can be elevated to become a pedagogical/cognitive tool to help in changing the focus of the classroom from one that is teacher-centered and controlled to one that is learner-centered and open to inquiry, dialogue, and creative thinking on the part of learners as active participants. Furthermore, they conclude that students are satisfy with of Google Classroom's thus show it is effective as an active learning tools. The research effort shows that we are constantly determine through observations, surveys, and analyses of student demography and course design to what leads to a greater student's satisfaction on method of learning. This approach, in turn, will contribute to the training of online instructors in methods and the designing of educational support programs that allow students to succeed in the online environment. It is timely that google classroom's tools should be integrated into the teaching and learning of data mining software, not solely because it is a useful utility tool [11].

This figure 3 below shows the features of the researcher's Google classroom in managing CCU and Introduction subject in 
2019 at the English Education Program, University of Brawijaya.

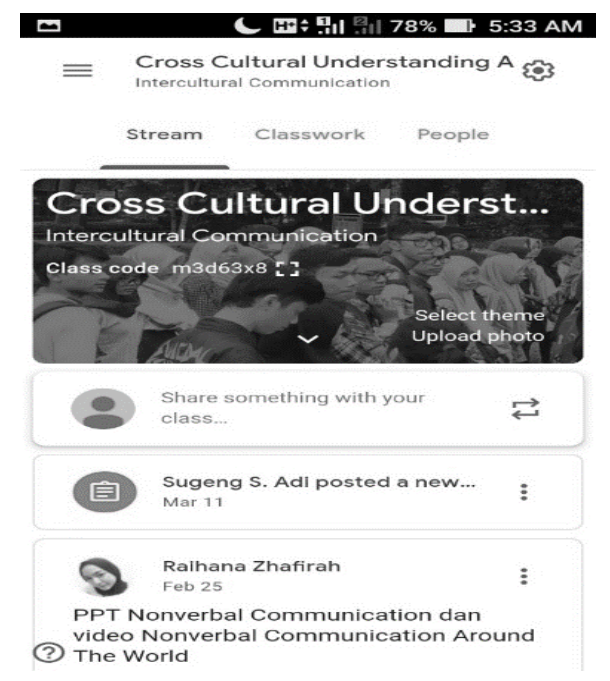

Fig. 3. Google Classroom for $\mathrm{CCU}$ and Introduction to Education

In these two subjects, $\mathrm{CCU}$ and Introduction to Education, the researcher mostly just utilizes sharing and questioning facilities provided by the media. The researcher as the teacher asks the students to post their comments on every posting both in the sharing and questioning facilities. Students are also provided with opportunities to share any format of materials related to the subjects, film, video, website link, news, or power point presentation for virtual classroom discussion.

This table 2 below describes the topic and quantity of student comments of CCU class A and Introduction to Education class C.

TABLE 2. TOPIC AND STUDENT COMMENTS

\begin{tabular}{|l|l|l|l|}
\hline \multicolumn{1}{|c|}{ Subject } & \multicolumn{1}{|c|}{ Topic } & Comments & Feedback \\
\hline $\begin{array}{l}\text { Cross Cultural } \\
\text { Understanding }\end{array}$ & Introduction to culture & 29 & 1 \\
\cline { 2 - 4 } A & Mid semester test & 32 & - \\
\hline $\begin{array}{l}\text { Introduction to } \\
\text { Education C }\end{array}$ & Schools & 24 & 1 \\
\cline { 2 - 4 } & Teacher roles & 11 & - \\
\cline { 2 - 4 } & Examination & 14 & - \\
\cline { 2 - 4 } & Mid-semester test & 29 & - \\
\cline { 2 - 4 } & Future of education & 20 & - \\
\cline { 2 - 4 } & $\begin{array}{l}\text { Intervention of } \\
\text { parents }\end{array}$ & 6 & - \\
\cline { 2 - 4 } & $\begin{array}{l}100 \text { smart students } \\
\text { tend to be stupid }\end{array}$ & 13 & - \\
\hline
\end{tabular}

Since blended learning could be defined as a mix of online and offline session, in these two subjects the researchers just uses the online meeting for posting teaching materials. Most discussion about the subjects' content are conducted at the offline session in the conventional classroom meetings.

\section{Student Learning Experiences}

Majority of students interviewed in this observation say that Google classroom is an excellent medium for social interaction (lecturer-students and students-student). Google classroom help me to submit assignment on time. The course activities helped me to examine issues, to evaluate new ideas, and to apply what I have learned. The feedback provided by the lecturer is useful. This paper found out that overall students are satisfy with of Google Classroom's thus show it is effective as an active learning tools. The research effort shows that we are constantly determine through observations, surveys, and analyses of student demography and course design to what leads to a greater student's satisfaction on method of learning. This approach, in turn, will contribute to the training of online instructors in methods and the designing of educational support programs that allow students to succeed in the online environment. It is timely that Google Classroom's tools should be integrated into the teaching and learning of data mining software, not solely because it is a useful utility tool.

Some students find that the Google Classroom is useful for them, Student A says that first time she has difficulty with the features of Google Classroom because it's a little bit different with Facebook. But, day by day she understands because I always open Google Classroom to learn each features of it. Student B says that she does not find any difficulties because in the first semester, her friend who studied at ABM started using Google Classroom for discussion and if teacher of certain subjects cannot attend, the lecturer uploads the material and the tasks that must be done by students. Besides, the students perceive that they have more freedom when expressing opinion in the Google Classroom rather in the offline session or conventional learning mode. The researcher finds that the pedagogical interaction is quite positive. The interaction is very important is teaching and learning process. Haryaka et al. [11] explain that the interaction must be had intends; engaged, paying attention, retaining the material that we are covering.

The student opinions can be described as follows:

Student $\mathrm{C}$ says that it is free if we give opinion in late night or in the time outside the class. "In other hand, expressing opinion orally in the traditional classroom setting is just in one time, I mean we only just have 120 minutes in the class to give an opinion. I think I'd better to use Google Classroom because it gives so much time to express an opinion than in the class".

Student D says that the differences are when they use Google Classroom we are not limited by time, the point here is if the lecturer cannot attend class, lecturer can upload assignments and materials through Google Classroom, because that the interaction between lecturer and students occur indirectly. It caused lecturer cannot give feedback.

When expressing opinion orally, we can discuss with other friend about the material and teacher also gives feedback. She feels confident if she expresses her opinion orally because I can know feedback from teacher and I immediately knew what my mistake. Expressing opinion orally in the traditional classroom setting consist of traditional learning. The second difference is 
expressing opinion using Google Classroom only in written form and can be done in everywhere, not only in classroom. Whereas expressing opinion orally in the traditional classroom setting can be done in written or spoken and only in classroom. The third difference is expressing opinion using Google Classroom by online, it means that indirectly. It is usually done by raising hand or the other quite signal. Between the two of the teaching models, the teaching model which is more confident in expressing my opinion is expressing opinion using Google Classroom. You must need internet connection and go online first when expressing opinion using Google Classroom, while in the traditional classroom setting you have to come to classroom first in the teaching and learning process directly. "I prefer expressing my opinion orally in the traditional classroom setting, because sometimes I can't go online, there is no internet connection in my home town, I should go to the nearest "warnet" (internet rental space) if I want to post my opinion".

\section{CONCLUSION}

Using ITC especially social media like in university classrooms currently is inevitable. The sophistication of technology enables both lecturers and students interact in synchronous and asynchronous learning mode. About the blended learning strategy applied in the course, students find it interesting to motivate their learning activities because the media used is similar to social media that have been very familiar with their daily life. The blended learning used in this CCU class is mediated by a social-media like, an educational online system called Edmodo. In this learning strategy students have a positive perception about the blended learning applied in the CCU classroom and Introduction to Education subject. Some students have difficulty in the beginning of using Google Classroom especially when they have to register and log in to the learning media; however, they can solve the problem by discussing their friends or doing trial and error. Students also perceive that they have more freedom when expressing opinion in the Google Classroom rather in the offline session or conventional learning mode. Finally, this research found that students have a positive attitude about studying.

\section{REFERENCES}

[1] P. McRae, "Blended learning: The great new thing or the great new hype," Retrieved from Washingt. Post http//www. washingtonpost. com/blogs/answer-sheet/wp/2015/06/21/blended-learning-the-great-newthing-or-the-great-new-hype/This Artic. was Print. S ummer, pp. 19-27, 2015.

[2] M. B. Horn and H. Staker, Blended: Using disruptive innovation to improve schools. John Wiley \& Sons, 2014.

[3] A. Hemmi, S. Bayne, and R. Land, "The appropriation and repurposing of social technologies in higher education," J. Comput. Assist. Learn., vol. 25, no. 1, pp. 19-30, 2009.

[4] H. B. Seta, T. Wati, A. Muliawati, and A. N. Hidayanto, "E-Learning Success Model: An Extention of DeLone \& McLean IS'Success Model," Indones. J. Electr. Eng. Informatics, vol. 6, no. 3, pp. 281-291, 2018.

[5] R. P. N. Puji and N. Umamah, "Edmodo Multimedia: Supporting Technology for Media Learning at Higher Education," Int. J. English Lit. Soc. Sci., vol. 3, no. 1.

[6] F. A. Mokhtar and H. Dzakiria, "Illuminating the potential of Edmodo as an interactive virtual learning platform for English Language learning and teaching," Malaysian J. distance Educ., 2015.

[7] K. A. Azhar and N. Iqbal, "Effectiveness of Google classroom: Teachers' perceptions," Prizren Soc. Sci. J., vol. 2, no. 2, pp. 52-66, 2018.

[8] F. Pradana, A. Rachmadi, and F. A. Bachtiar, "Penilaian Faktor Penerimaan Teknologi Blended learning di PTIIK Universitas Brawijaya dengan Metode Unified Theory of Acceptance and Use of Technology (UTAUT)," J. Teknol. Inf. dan Ilmu Komput., vol. 2, no. 1, pp. 49-58, 2015.

[9] M.-L. Hung, "Teacher readiness for online learning: Scale development and teacher perceptions," Comput. Educ., vol. 94, pp. 120-133, 2016.

[10] I. N. M. Shaharanee, J. M. Jamil, and S. S. M. Rodzi, "Google classroom as a tool for active learning," in AIP Conference Proceedings, 2016, vol. 1761, no. 1, p. 20069.

[11] U. Haryaka, F. Agus, and A. H. Kridalaksana, "User satisfaction model for e-learning using smartphone," Procedia Comput. Sci., vol. 116, pp. 373380,2017 